Karlsruher Institut für Technologie

\title{
SIRHEX - a new experimental facility for high heat flux testing of plasma facing components
}

\author{
André Kunze ${ }^{1}$, Bradut-Eugen Ghidersa ${ }^{1}$, Flavia Bonelli ${ }^{2}$
}

${ }^{1}$ Institute for Neutron Physics and Reactor Technology - Karlsruhe Institute of Technology (KIT), Germany, Corresponding author: andre.kunze@kit.edu

SIRHEX ("Surface Infrared Radiation Heating Experiment") is a small-scale experimental facility at KIT, which has been built for testing and qualifying high heat flux radiation heaters for blanket specific conditions using an instrumented water cooled target.

In the first series of tests a commercial infrared heater is tested to answer the following questions:

- Is it possible to reach heat flux densities up to $500 \mathrm{~kW} / \mathrm{m}^{2}$ at a temperature of $500^{\circ} \mathrm{C}$ on the surface of the target?

- How homogeneous is the heat distribution?

- How many cycles is the heater able to withstand?
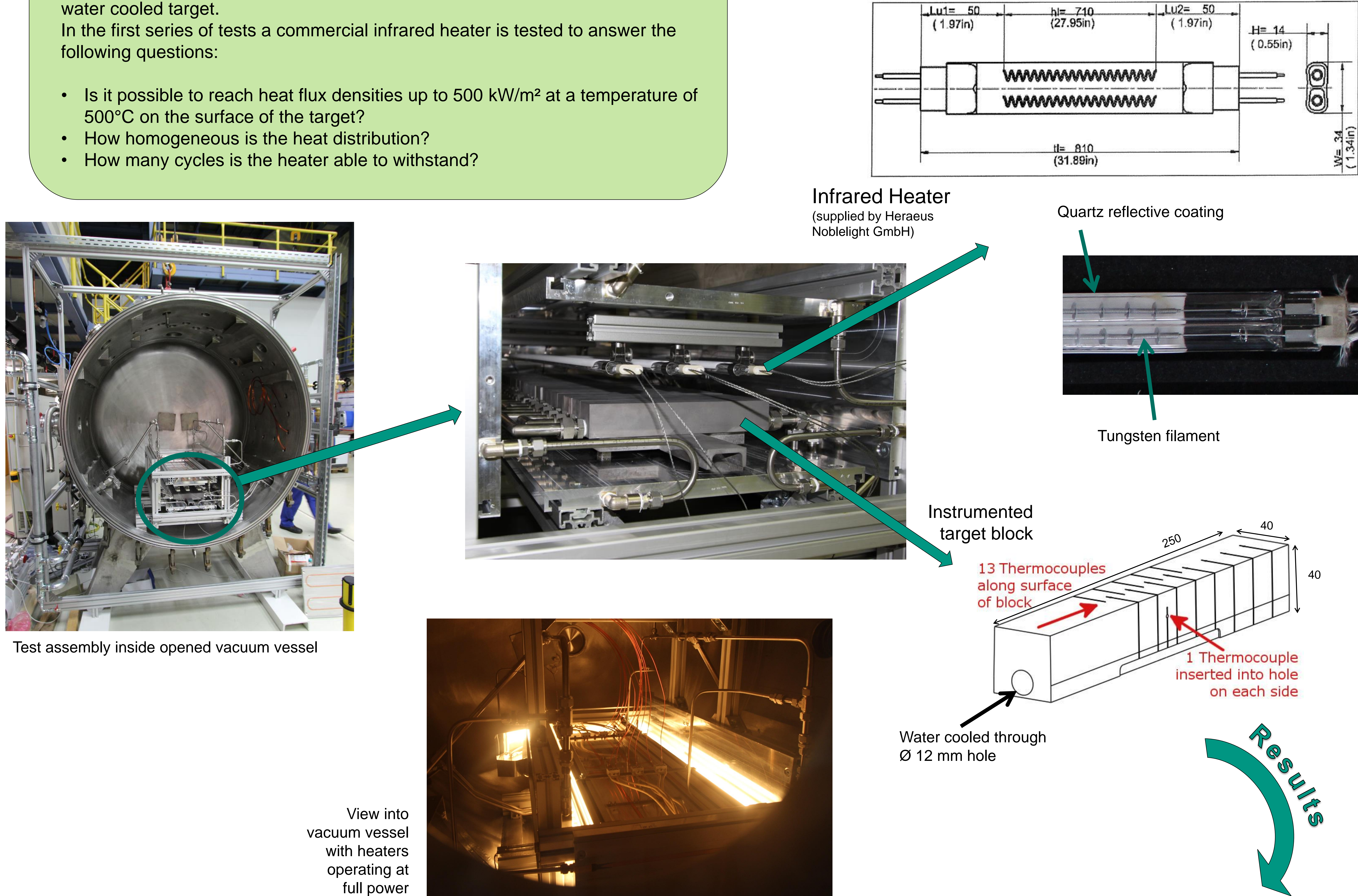

Infrared Heater (supplied by Heraeus

uartz reflective coating

Test assembly inside opened vacuum vessel

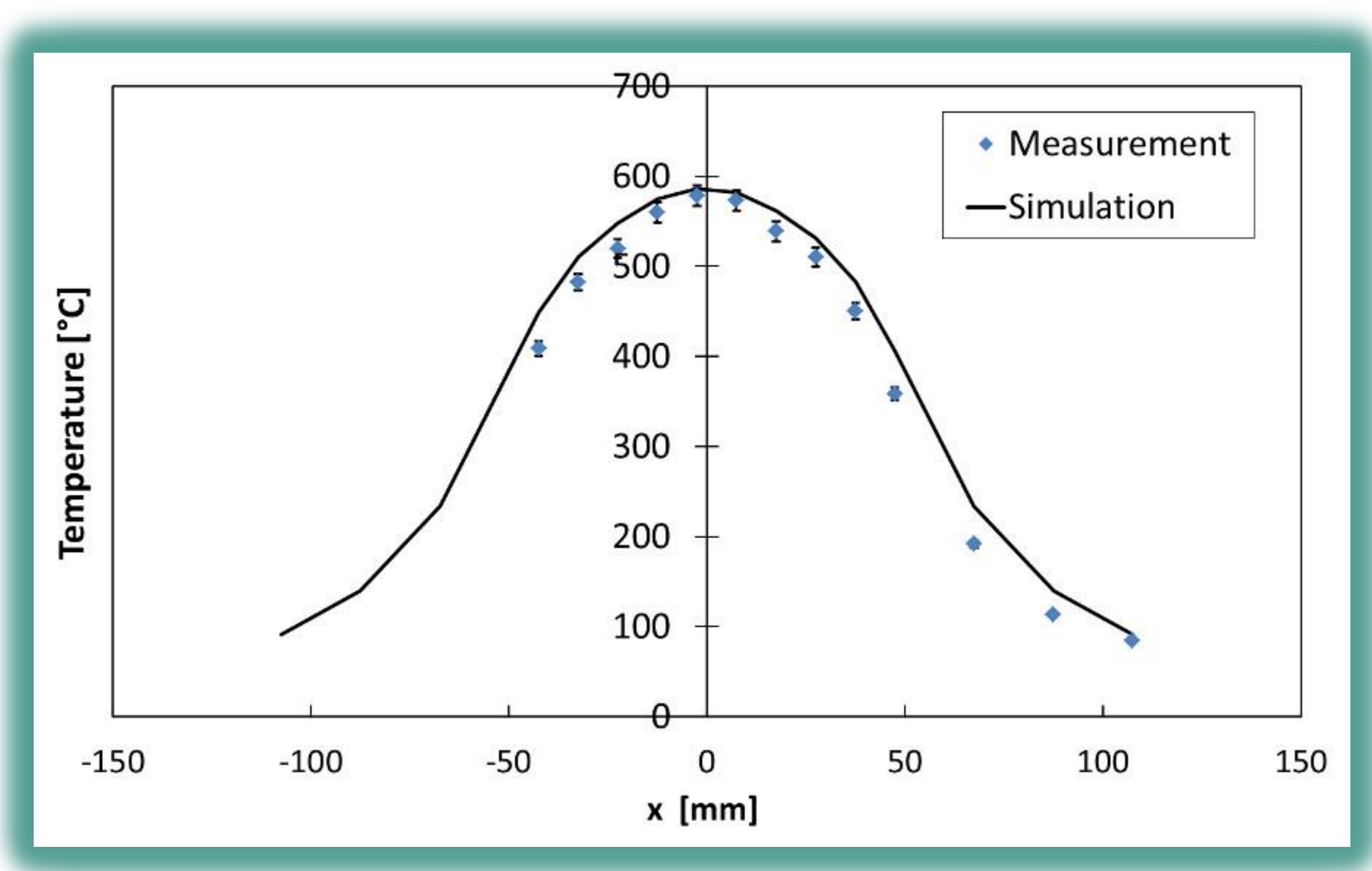

Steady state

temperature

$800 \mathrm{~s}$

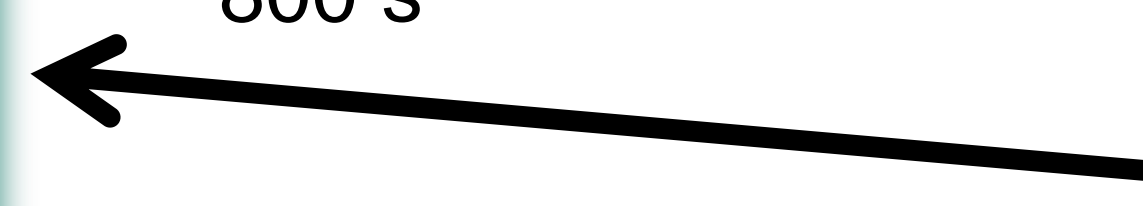

Steady state heat

flux after $800 \mathrm{~s}$
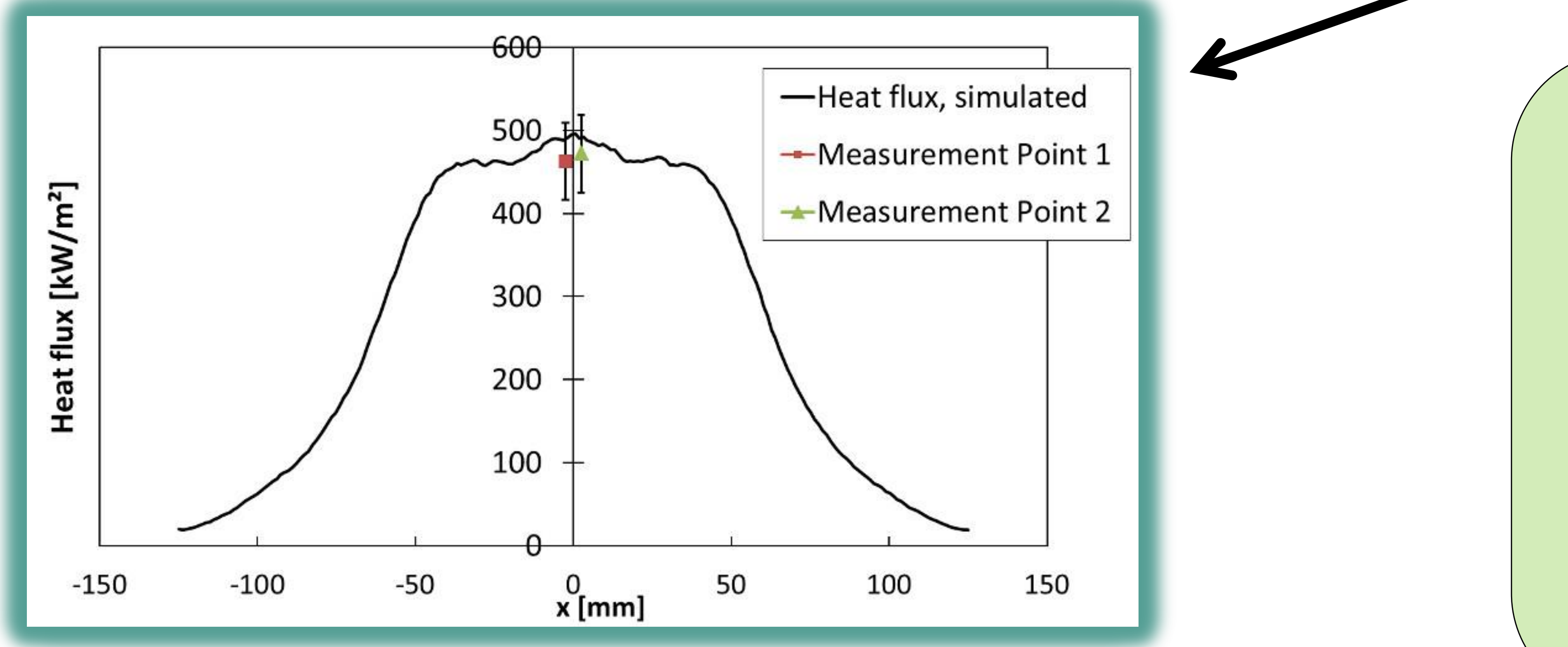

\begin{tabular}{|c|c|c|}
\hline \multicolumn{3}{|c|}{ Summary } \\
\hline & Goals & Achieved \\
\hline Surface heat flux & $500 \mathrm{~kW} / \mathrm{m}^{2}$ & $470 \mathrm{~kW} / \mathrm{m}^{2}$ \\
\hline Surface temperature & $500^{\circ} \mathrm{C}$ & $>550^{\circ} \mathrm{C}$ \\
\hline $\begin{array}{l}\text { Homogeneity of heat } \\
\text { distribution }\end{array}$ & $+/-5 \%$ of nominal value & $\begin{array}{l}+5.2 /-3 \% \text { of average } \\
\text { value (below heaters) }\end{array}$ \\
\hline Lifetime & $\begin{array}{l}3000 \text { cycles with } 400 \mathrm{~s} \\
\text { at max. power }\end{array}$ & 226 cycles \\
\hline
\end{tabular}

